University of Nebraska - Lincoln

DigitalCommons@University of Nebraska - Lincoln

Robert Katz Publications

Research Papers in Physics and Astronomy

October 1966

\title{
Simulated Radioactivity
}

Robert Katz

University of Nebraska-Lincoln, rkatz2@unl.edu

J. J. Butts

Kansas State University, Manhattan, Kansas

Follow this and additional works at: https://digitalcommons.unl.edu/physicskatz

Part of the Physics Commons

Katz, Robert and Butts, J. J., "Simulated Radioactivity" (1966). Robert Katz Publications. 2.

https://digitalcommons.unl.edu/physicskatz/2

This Article is brought to you for free and open access by the Research Papers in Physics and Astronomy at DigitalCommons@University of Nebraska - Lincoln. It has been accepted for inclusion in Robert Katz Publications by an authorized administrator of DigitalCommons@University of Nebraska - Lincoln. 


\title{
Simulated Radioactivity
}

\author{
Robert Katz and J. J. Butts
}

\begin{abstract}
An experiment to simulate radioactive decay is easily performed with a random-number generator or a set of random numbers. The nuclei are imagined to be indexed consecutively. The initial appearance of the index number of a particular nucleus is interpreted as a signal that it has disintegrated. The number of surviving nuclei is an exponential function of the number of draws, and represents the radioactive decay law, with fluctuations. This procedure is a precise realization of the conventional probabilistic derivation of the radioactive decay law if, indeed, the random number generator is truly unbiased.
\end{abstract}

doi:10.1119/1.1972363

Published in American Journal of Physics 34:10 (October 1966), p. 986 . Copyright (C) 1966 American Association of Physics Teachers. Used by permission. 
consecutively. The initial appearance of the index number of a particular nucleus is interpreted as a signal that it has disintegrated. The number of surviving nuclei is an exponential function of the number of draws, and represents the radioactive decay law, with fluctuations. This procedure is a precise realization of the conventional probabilistic derivation of the radioactive decay law if, indeed, the random number generator is truly unbiased.

In the probabilistic derivation of radioactive decay we assume that the probability $p$ for a disintegration to take place in an interval $\Delta t$ is $\lambda \Delta t$, so that in a time $t=n \Delta t$ the probability for survival is $(1-p)^{n}$. Noting that $(1-p)^{n}$ $=1-n p+n(n-1) p^{2} / 2$, and $e^{-n p}=1-n p+n^{2} p^{2} / 2^{\lambda}$, we approximate the binomial by the exponential for large $n$ and small $p$. Thus we write the survival probability as $e^{-n p}=e^{-\lambda t}$.

Any of a large variety of random-number generators or random-number tables may be used in the simulation. One such generator may be made from a turntable-spindle arrangement, as in an automatic record player, or the PSSC angular-momentum apparatus. The turntable is provided with a radially subdivided mat containing, say, 120 divisions (making $p=1 / 120$ ). The table is spun manually, and a pointer is dropped down the spindle to come to rest at the generated number.

Each member of an initial population of, say, 100 nuclei is taken to survive until its. index number is generated. In any spin the appearance of the number of a nucleus which has already disintegrated, or of a number not assigned to any nucleus simply increases the number of spins without decreasing the number of surviving nuclei.

Two plots obtained by students in general physics laboratories in an initial trial of this experiment are shown in Fig. 1.

We are indebted to R. E. Green for developing these suggestions into a student experiment.

* Sponsored by the National Science Foundation and National Aeronautics and Space Sdministration.

\section{Simulated Radioactivity*}

ROBERT KATZ AND J. J. ButTS Kansas State University, Manhattan, Kansas

$A^{2}$ $\mathrm{N}$ "experiment" to simulate radioactive decay is easily performed with a random-number generator, or a set of random numbers. The nuclei are imagined to be indexed

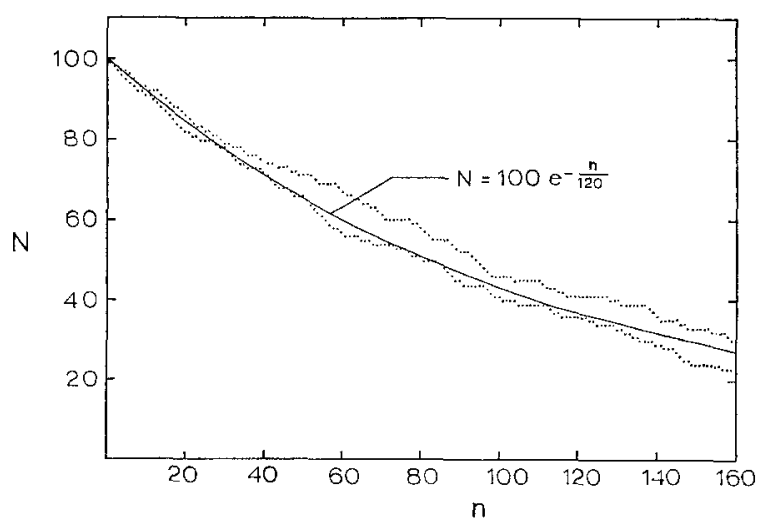

Frg. 1. The number $N$ of surviving nuclei of an initial population of 100 after $n$ spins of a turntable-spindle-pointer random-number generator having 120 equally likely options. The solid curve represents the exponential approximation to the expected outcome while the two dotted curves are outcomes of student experiments simulating radioactive decay. 